\title{
Stage IB Vaginal Cancer AJCC v8
}

National Cancer Institute

\section{Source}

National Cancer Institute. Stage IB Vaginal Cancer A/CC v8. NCI Thesaurus. Code C139660.

Stage IB includes: T1b, N0, M0. T1b: Tumor confined to the vagina, measuring more than $2.0 \mathrm{~cm}$. N0: No regional lymph node metastasis. M0: No distant metastasis. (AJCC 8th Ed.) 